\title{
APRESENTAÇÃO DE LIVROS
}

Lucía Martínez Moctezuma

Universidad Autónoma del Estado de Morelos, México

luciamm@uaem.mx

Vimos por esta divulgar o lançamento de quatro novos livros:

Denise Bernuzzi de Sant'Anna

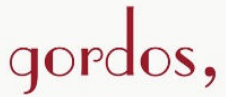

magros e

obesos
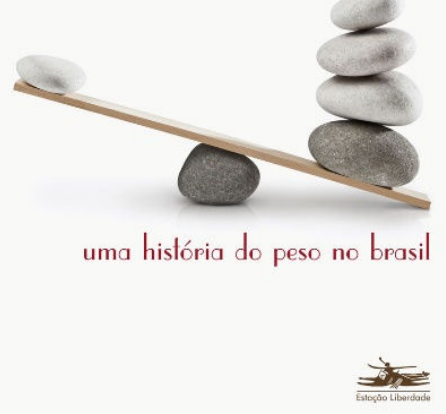

SANT'ANNA, Denise Bernuzzi de. Gordos, magros e obesos - Uma história do peso no Brasil. São Paulo: Estação Liberdade, 2016. ISBN: 978-85-7448-273-6

$\mathrm{Na}$ era dos Bourbons, Orleans e Bragança, a noção de magreza no Brasil denotava uma ameaça à reprodução saudável da espécie. A mídia da época, ao noticiar sobre os banquetes daquelas elites, saudava as iguarias preparadas à base de banha de porco como forma de ratificar no inconsciente coletivo o ideal de bonança, a imagem própria da felicidade na forma de fartura. Com o passar dos anos, no entanto, as relações - sempre íntimas - entre alimentação, obesidade e sucesso incorporaram outros valores, mudando de perspectiva de forma radical. É essa a jornada destrinchada por Denise Bernuzzi de Sant'Anna neste Gordos, magros e obesos - Uma história do peso no Brasil.

O livro propõe uma viagem fascinante sobre como o peso do corpo de um sujeito "fala" sobre o tempo em que ele vive e o impacto disso em suas relações sociais. Aborda também as alterações dos hábitos alimentares no país ao longo do século $\mathrm{XX}$, cujas consequências, fatalmente, estão sempre atreladas à balança. Se hoje em dia "acusamos" alguém de ser "magro de ruim", pela inveja que sentimos de sua compleição física sem excessos, em outros tempos a expressão guardava outra conotação, no caso, quase literal: em especial as mulheres tidas como "magras de ruim" seriam vorazes, avarentas e ambiciosas, mais tinhosas do que as mulheres "normais", pois suas silhuetas teimariam em permanecer como eram, em peso e volume, independente do que comessem. Ilesas às consequências da gula, eram associadas a uma espécie 
de encarnação do mal e, para se esquivarem dessa imagem, recorriam a qualquer expediente que lhes prometesse o sobrepeso do bem.

A autora repassa no livro os episódios mais representativos em que gordos e magros se revezaram no protagonismo de suas aparências físicas conforme as mudanças, sempre muito rápidas, de paradigmas. Entre estes, destacam-se a difusão das balanças nas drogarias, e a posterior massificação das balanças pessoais portáteis, que contribuíram para desenvolver o hábito nas pessoas de medirem o próprio peso com regularidade; a associação do gordo com a noção de fracasso - e a consequente banalização das dietas e outros estratagemas para emagrecer, que acabariam estimulando a perigosa tendência contemporânea dos adeptos à anorexia e à bulimia; e o despontamento de uma "geração saúde", em que a ambição pela barriga tanquinho ou pelo tórax dos deuses nas academias criaram um ser híbrido, que não se quer magro nem obeso, focado que está na busca do corpo "malhado".

Objeto recorrente de pesquisas científicas e alvo de debates acalorados sobre ser, ou não, doença endêmica, a obesidade estimula mais do que meras discussões sobre estética e autoestima. Dos antigos licores para engordar às dietas contemporâneas, cirurgias e alimentos diet, mudaram não apenas os critérios de saúde e beleza, mas também o modo de conceber a decência, o pudor e a sexualidade a partir da forma física. Novos perigos nunca antes imaginados na alimentação cotidiana são revelados com frequência. Este livro propõe, portanto, reflexões sobre o peso que extrapolam o desenho visível das silhuetas.

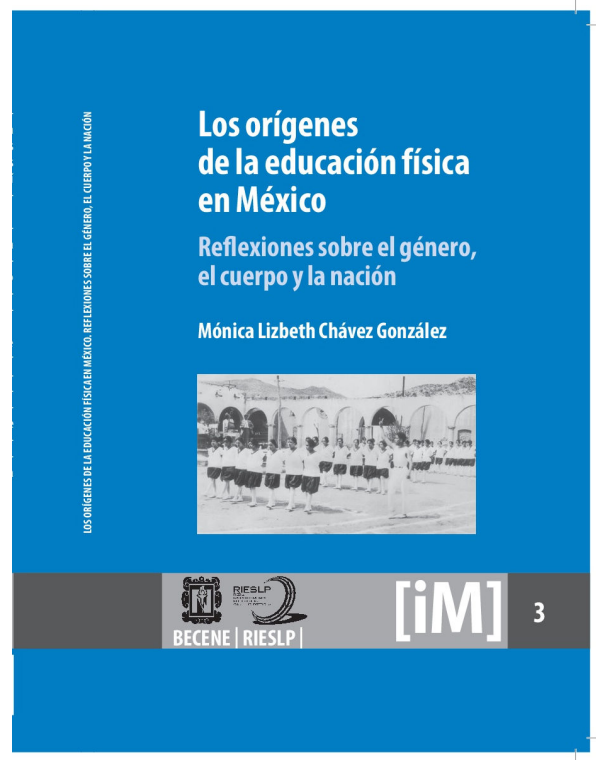

CHÁVEZ GONZÁLEZ, Mónica Lizbeth. Los orígenes de la educación física en México. Reflexiones sobre el género, el cuerpo y la nación. México: Red de investigadores de San Luis Potosí, Benemérita y Centenaria Escuela Normal del Estado, Universidad Autónoma de México, 2015. ISBN: 978-607-02-7584-5

Este libro ofrece un recorrido en el tiempo por los orígenes de la educación física en México con la intención de problematizar las implicaciones socioculturales implícitas en una disciplina escolar y colocar estas reflexiones al alcance de especialistas en la investigación educativa así 
como de los docentes y alumnos que están en proceso de formación en este campo de la enseñanza.

La educación física es una disciplina escolar que ha ocupado diferentes posiciones en el currículo oficial del sistema educativo mexicano. Por mucho tiempo pareció ser una materia de segunda importancia en las escuelas del nivel básico en comparación con aquellas que representaban los conocimientos científicos como las matemáticas, el español, las ciencias naturales e incluso la historia y la geografía.

Detrás de cada una de las disciplinas escolares existe una serie de representaciones sociales que permiten entender la articulación entre las prácticas escolares y el contexto sociocultural de una época. Más allá de las justificaciones pedagógicas que se promueven en cada disciplina, éstas encierran concepciones sobre el deber ser de la sociedad en general, que permiten entender el papel que ha desempeñado la institución escolar en la conformación de subjetividades y comportamientos culturales, en este caso, se abordarán las relativas a la construcción de la nación, el género y el cuerpo.

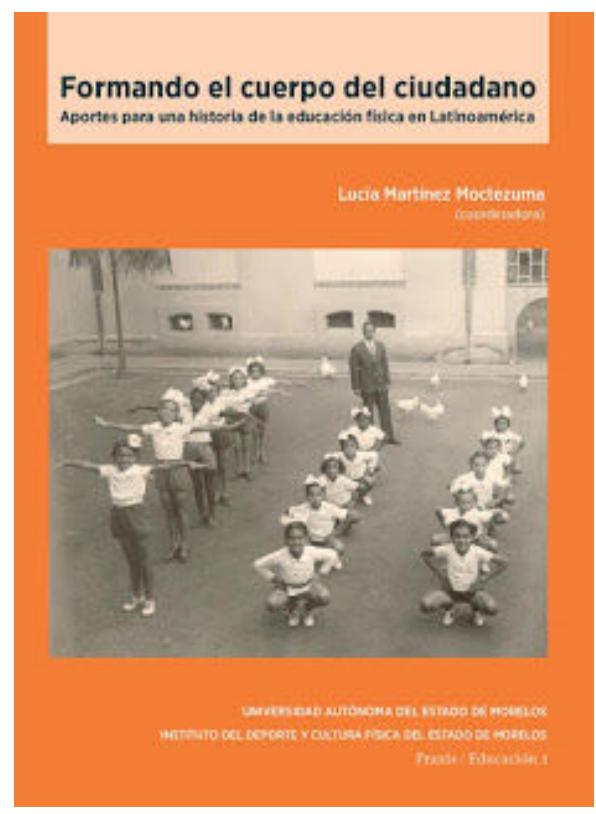

MARTÍNEZ MOCTEZUMA, Lucía. Formando el cuerpo del ciudadano. Aportes para una historia de la educación física en Latinoamérica. México: UAEM, Instituto del Deporte y Cultura Física del Estado de Morelos, 2016. ISBN: 978-607-8434-65-7

En el verano de 1893, el periodista, escritor y senador francés Hugues Le Roux realizó un viaje de estudios al norte de Europa para conocer los avances en la enseñanza de la gimnasia. Tradujo sus impresiones en un informe que revelaba su entusiasmo con este descubrimiento: el perfeccionamiento del hombre común se logra con la práctica de la gimnasia científica de Ling. Pero el interés no fue circunstancial, porque estas novedades se difundieron también en América Latina. En México se publicó muy pronto uno de los primeros libros de esta disciplina, cuya traducción al castellano era de la autoría del argentino Domingo Faustino Sarmiento: La gimnasia sueca. Manual de gimnasia racional al alcance de todos y para todas las edades, escrito por dos de los seguidores de Ling, L. G. Kumlien y Emile André. Desde entonces, 
maestros, médicos y autoridades educativas escribieron, tradujeron y adaptaron otros textos pero también discutieron y diseñaron planes y programas que atendían el mejoramiento intelectual, moral y físico del ciudadano americano. ¿Cómo circularon estos saberes?, ¿cómo se adaptaron?, ¿en qué condiciones se practicaron en las salas de clase? Estas son algunas de las preguntas a las que hemos querido responder un grupo de especialistas en el tema. Con este libro queremos discutir y analizar los cuerpos desde una óptica social, cultural e histórica. Examinamos actores, instituciones, discursos y políticas, configurados en torno a una disciplina escolar en particular y a la cultura física en general, identificando las disputas, los sentidos y los significados particulares no sólo sobre los cuerpos, sino también sobre los géneros, la moral, la política y la nación.

Los capítulos que forman esta obra son:

\section{Palabras preliminares}

Pablo Scharagrodsky y Lúcía Martínez Moctezuma

\section{Introducción}

Quando é possivel formar os corpos? Uma introdução ao tema na América Latina Marcus Aurelio Taborda de Oliveira

\section{DISCURSOS Y POLÍTICAS}

"Ser fuerte para ser útil". Debates sobre política y gobierno de los cuerpos en la profesionalización de la Educación Física argentina (1910-1940)

Eduardo Galak

Educación del cuerpo y discursividades en torno a la formación docente en la creación del Curso de Profesores de Educación Física en el Uruguay (1939-1948)

Paola Dogliotti Moro

Cartografiando, acciones, significados y disputas en el campo de la cultura física argentina. El caso de la Asociación de Profesores de Educación Física en las primeras décadas del siglo XX Pablo Ariel Scharagrodsky

Preocupaciones, intenciones, ilusiones

César Federico Macías Cervantes

\section{DISCURSOS, ACTORES E INSTITUCIONES}

Educación Física en Chile: Una historia construida entre la academia y una raza óptima para producción del mercado 
Carolina Poblete Gálvez

Discursos sobre la educación fisica y la salud corporal de la infancia mexicana, a finales del siglo XIX

Luz Elena Galván Lafarga

Imagénes de la educación fisica infantil en el archivo Augusto Malta (Rio de Janeiro, 19031936)

Tarcisio Mauro Vago

Medicina y educación física en Colombia: Discursos y prácticas de subjetivación en la obra de Jorge Bejarano

Claudia Ximena Herrera Beltrán

\section{MODELOS PEDAGÓGICOS Y PRÁCTICAS}

Outros contornos para as Histórias da Educação Física no Brasil: indícios de referenciais estadunidenses na escolarização da disciplina em Minas Gerais

Giovanna Camila da Silva

Tránsito de sujetos y métodos norte-americanos: propuestas para la enseñanza de la Educación Física dentro y fuera de las escuelas brasileras

Meily Assbú Linhales

La influencia protestante y del movimiento asociacionista de Springfield College en la educación del cuerpo y la educación física en el Uruguay

Paola Dogliotti Moro

Paula Malán

El cambio hacia un modelo norteamericano de educación fisica: las Misiones Culturales en el México rural, 1923-1940

Lucía Martínez Moctezuma

\section{OTROS PROBLEMAS, NUEVAS PERSPECTIVAS}

La historia de la educación física: el ejemplo francés y las perspectivas internacionales de investigación

Jean Saint-Martin y Michaël Attali 


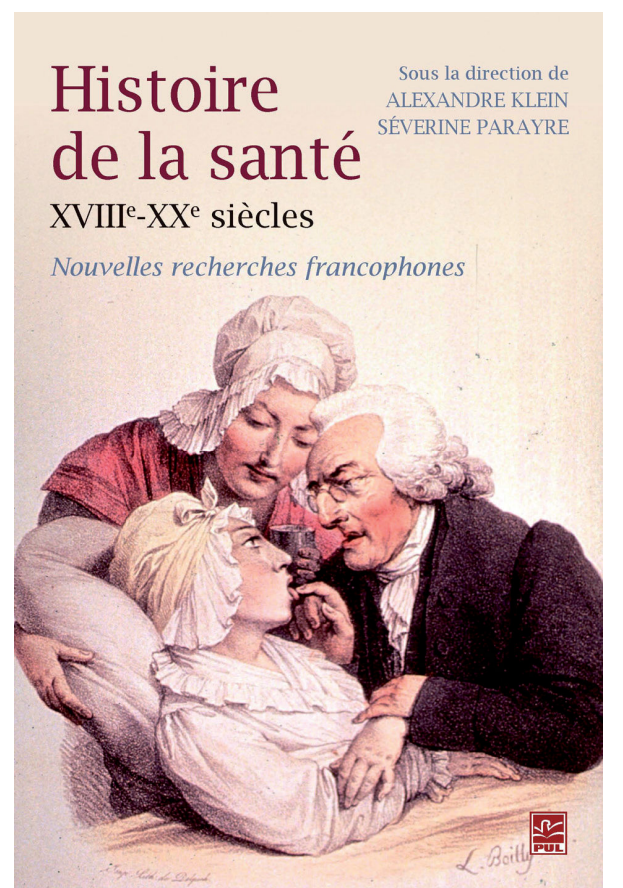

KLEIN, Alexandre; PARAYRE, Séverine (dir.). Histoire de la Santé XVIIIe-XXe siecle. Nouvelles recherches francophones. Canada: PUL, 2016. ISBN: 978-2-76372127-9

L'histoire de la médecine, activité longtemps réservée et consacrée aux seuls médecins, a connu depuis un demisiècle de nombreuses mutations. Investie par les historiens, les philoso-phes et diverses sciences sociales, elle s'est progressivement développée sous la forme d'une histoire de la santé visant à comprendre comment les hommes et les femmes du passé vivaient, pensaient et agissaient pour maintenir, recouvrer ou améliorer leur santé. Au sein de ce domaine de recherche en pleine expansion, les travaux francophones se sont multipliés depuis le début du xxie siècle, dessinant les contours d'une historiographie singulière. C'est un panorama de ces recherches francophones en histoire de la santé à l'époque moderne et contemporaine que propose cet ouvrage collectif. Résultat des activités du réseau de recherche Historiens de la santé, il présente une sélection de travaux originaux réalisés par des chercheuses et des chercheurs francophones issus de différents pays, afin de témoigner de la vitalité de l'histoire francophone de la santé.

\section{Table des matiers}

Pour une histoire francophone, globale et inclusive, de la santé

Alexandre Klein et Séverine Parayre

\section{OUVERTURE}

Dominances et émergences en histoire des pratiques de santé au Québec: les thématiques et approches actuelles

François Guérard

\section{INSTITUTIONS, SOINS ET PRÉVENTION}

"Elles auront soin de ne pas les laisser manger tous vivants par les poux et la vermine": la contagion dans les institutions hospitalières du XVIIIe siècle

Claire Garnier

Prendre soin à l'école: naissance de l'éducateur en santé (France, XIXesiècle) 
Séverine Parayre

De l'expérience de la tuberculose aux pratiques de santé d'Élise Freinet. Éléments pour comprendre une autre éducation à la santé

Xavier Riondet

\section{LA PAROLE DES MALADES}

"Il est clair que je suis hypocondre vaporeux, et peut-etre pis encoré". De l'agentivité des malades impatientsdu Dr.Tissot (1728-1797)

Alexandre Klein

Des existences et des singularités dans le discours historique ». Les lettres de Marguerite-Marie, 1921-1950

Marie-Claude Thifault

\section{LE POINT DE VUE DES MÉDECINS}

Aux prémices de la démocratie sanitaire. La révolution des normes sociales dans la médecine du peuple du Dr.Tissot (1728-1797)

Alexandre Klein

L'histoire méconnue des premiers médecins en nutrition. Le Docteur Marcel Labbé (1870-1939), promoteur de la diététique du diabète et de l'alimentation rationnelle en France au début du XXe siècle

Claire Marchand

\section{MÉDIAS ET MÉDIATIONS}

Pour une histoire des pratiques de santé. L'exemple de la publicité

Didier Nourrisson

“Aspirine arrête la douleur vite!”. Souffrance et soulagement dans les publicités pour Aspirine au Québec, 1920-1970

Denyse Baillargeon

Une histoire de poids: l'obèse, le mince et le fort au Brésil

Denise Bernuzzi de Sant'Anna 